24 Orfan N, Patterson R, Dykewicz MS. Severe angioedema related to ACEinhibitors in patients with a history of idiopathic angioedema. $\mathcal{F A M A}$ 1990;264:1287-9.

25 Sears M. Epidemiological trends in bronchial asthma. In: Kaliner MA, Barnes PJ, Persson CG, eds. Asthma. Its pathology and treatment. New York: Marce Dekker Inc, 1991:1-41.

26 Rucinska EJ, Small R, Mulcahy WS, Snyder DL, Rodel PV, Rush JE, et al. Tolerability of long-term therapy with enalapril maleate in patients resistan to other therapies and intolerant to captopril. Medical Toxicology and Adverse Drug Experiments 1989;4:144-52.
27 Schrör K. Converting enzyme inhibitors and the interaction between kinins and eicosanoids. F Cardiovasc Pharmacol 1990;15 (suppl 6): $\mathrm{S60}-8$.

28 Donaldson VH, Evans RR. A biochemical abnormality in hereditary angioneurotic oedema: absence of serum inhibitor of $\mathrm{Cl}$-esterase. Am $\mathcal{J} \mathrm{Med}$ 1963;35:37-44.

29 Erdös EG. Some old and some new ideas on kinin metabolism. $\mathcal{F}$ Cardiovasc Pharmacol 1990;15 (suppl 6):S20-4

\title{
Randomised controlled trial of atenolol and pindolol in human pregnancy: effects on fetal haemodynamics
}

\author{
Sven Montan, Ingemar Ingemarsson, Karel Maršál, Nils-Otto Sjöberg
}

\section{Abstract}

Objective-To compare the effects of uteroplacental circulation of two $\beta$ adrenoceptor blockers, atenolol (cardioselective) and pindolol (non-selective with intrinsic sympathomimetic activity).

Design-Controlled double blind double dummy study.

Setting-Departments of obstetrics and gynaecology in two Swedish university hospitals.

Subjects-29 women with pregnancy induced hypertension in the third trimester, 13 randomised to atenolol and 16 to pindolol.

Main outcome measures-Pulsatility index in fetal aorta, umbilical artery, and maternal arcuate artery. Volumetric blood flow in fetal aorta and umbilical vein.

Results - Mean arterial blood pressure decreased by $9.0(95 \%$ confidence interval -13.0 to $-5.0) \mathrm{mm} \mathrm{Hg}$ in the atenolol group and by 7.8 $(-11.4$ to -4.2$) \mathrm{mm} \mathrm{Hg}$ in the pindolol group. During atenolol treatment the pulsatility index increased significantly from 1.82 (SD 0.20 ) to 2.07 $(0.32)$ in the fetal thoracic descending aorta, from $1.44(0.28)$ to $1.79(0.27)$ in the abdominal aorta, and from $0.93(0.17)$ to $1.05(0.19)$ in the umbilical artery; the volumetric blood flow in the umbilical vein decreased from $106(28.8)$ to $84(22.6) \mathrm{ml} / \mathrm{min} / \mathrm{kg}$. No such changes were seen after treatment with pindolol. Birth weight was similar in the two groups but placental weight was significantly different $(529$ (122) $\mathrm{g}$ in atenolol group $v 653(136) \mathrm{g}$ in pindolol group; $\mathbf{p}=\mathbf{0} \cdot 03$ ).

Conclusion-The hypotensive effect was similar with both drugs, but only the $\beta_{1}$ blocker atenolol had significant effects on fetal haemodynamics, although within normal ranges. The implications of these findings can be only speculative, but negative fetal consequences of $\beta_{1}$ adrenoceptor blockade cannot be excluded.

and Gynaecology

University Hospital

S-22185 Lund, Sweden

Sven Montan, senior lecturer

Ingemar Ingemarsson,

associate professor

Nils-Otto Sjöberg, professor

Department of Obstetrics and Gynaecology, Malmö

University Hospital,

Malmö, Sweden

Karel Maršál, associate professor

Correspondence and requests for reprints to: Dr Montan. asphyxia. ${ }^{45}$ Furthermore, in pregnant women with hypertension in the third trimester, atenolol increased

A few studies on $\beta$ blockers with intrinsic sympathofetal and uteroplacental peripheral vascular resistance. ${ }^{6}$ mimetic activity, such as pindolol, ${ }^{7}$ and with $\alpha_{1}$ blocking activity, such as labetalol, ${ }^{8}$ using a gammacamera have suggested that they produce little change of uteroplacental blood flow. We compared two $\beta$ blockers with different actions, atenolol and pindolol. We studied maternal as well as fetal haemodynamics in women with pregnancy induced hypertension by using Doppler ultrasonography.

\section{Patients and methods}

The study included 32 women who were normotensive in the first trimester and who were admitted to our hospitals with pregnancy induced hypertension (blood pressure $140 / 90 \mathrm{~mm} \mathrm{Hg}$ or more on two occasions four hours or more apart). Women who had sustained hypertension after three days' rest in hospital, who met none of the exclusion criteria, and who agreed to participate in the study after being given oral and written information were included. The mean gestational age at admission was 35 (range 33-38) completed weeks. Exclusion criteria were multiple gestation, diastolic blood pressure $110 \mathrm{~mm} \mathrm{Hg}$ or more, estimated fetal weight deviation of more than $-22 \%$ ( 2 SD from estimated mean weight for gestational age), gestational age at recruitment less than 32 weeks, other drug treatment, contraindications to prolonging the pregnancy, or giving $\beta$ blockers. The women were randomly allocated to antihypertensive treatment with either atenolol or pindolol. A double blind double dummy technique was used to allocate the antihypertensive drugs. Information on which treatment the women were given was stored in sealed envelopes and these were not opened until the study was completed. Two patients in the atenolol group had only one blood flow velocity measurement and were excluded; one was delivered within one week and the other rejected further participation in the study. One patient in the pindolol group was excluded because of side effects (tachycardia). Thus 29 patients participated in the study: 13 in the atenolol group and 16 in the pindolol group.

All pregnancies were dated by ultrasound measurement of the fetal biparietal diameter in the first half of gestation. Before women were entered into the study, fetal weight was estimated from the biparietal diameter and the mean abdominal diameter. ${ }^{9}$ None of the fetuses was small for gestational age-that is, with weigh more than 2 SD below the mean. Seven women had proteinuria (three in the atenolol group and four in the pindolol group).

Bedrest and limited activity was advised during the first three days in hospital. Blood pressure was measured four times daily with the patient in a semirecumbent position by a mercury sphygmomanometer with appropriate cuff. Korotkoff phase 5 was used as an indicator of diastolic blood pressure. Mean 
arterial blood pressure (diastolic pressure + (systolic pressure-diastolic pressure)/3) was calculated and maternal heart rate was counted at each blood pressure recording. Electronic monitoring of fetal heart rate, fetal movements, and uterine contractions (non-stress test) was done daily in all women from day of recruitment to delivery. Antihypertensive drugs were given orally twice daily, atenolol $50 \mathrm{mg}$ or pindolol $5 \mathrm{mg}$, for at least a week. Women received no additional oral antihypertensive treatment.

Blood flow was measured as described by Eik-Nes et $a l^{10}$ with a real time linear array scanner (ADR, Model 2130, Advanced Diagnostic Research Corporation, Tempe, Arizona; $2 \mathrm{MHz}$ ) in combination with a pulsed Doppler instrument (ALFRED, Vingmed, $\mathrm{A} / \mathrm{S}$, Oslo, Norway; $3.5 \mathrm{MHz}$ ). The recorded mean blood velocity was then corrected for the $45^{\circ}$ insonation angle, thus giving the true blood velocity in the vessel

TABLE I-Characteristics of women randomised to receive atenolol or pindolol for pregnancy induced hypertension

\begin{tabular}{|c|c|c|}
\hline & $\begin{array}{l}\text { Atenolol } \\
\text { group } \\
(\mathbf{n}=13)\end{array}$ & $\begin{array}{l}\text { Pindolol } \\
\text { group } \\
(n=16)\end{array}$ \\
\hline No primiparous & 12 & 11 \\
\hline Mean (range) maternal age (years) & $27 \cdot 2(22-39)$ & $27.9(19-37)$ \\
\hline Mean $(\mathrm{SD})$ maternal weight $(\mathrm{kg})$ & $63 \cdot 3(14 \cdot 1)$ & $66 \cdot 8(12 \cdot 9)$ \\
\hline No of smokers & 2 & 5 \\
\hline $\begin{array}{l}\text { Mean (SD) gestational age at first blood flow } \\
\text { measurement (weeks) }\end{array}$ & $35 \cdot 8(1 \cdot 5)$ & $35 \cdot 9(1 \cdot 6)$ \\
\hline $\begin{array}{l}\text { Mean (range) duration of antihypertensive } \\
\text { treatment (days) }\end{array}$ & $16 \cdot 6(5-43)$ & $18 \cdot 4(4-44)$ \\
\hline Mean (SD) gestational age at delivery (days) & $271 \cdot 7(6 \cdot 6)$ & $274 \cdot 2(6 \cdot 1)$ \\
\hline
\end{tabular}

TABLE II - Maternal haemodynamics before and during treatment of hypertension

\begin{tabular}{|c|c|c|c|c|c|}
\hline & \multicolumn{2}{|c|}{ Atenolol group } & \multicolumn{2}{|c|}{ Pindolol group } & \multirow[b]{2}{*}{$\begin{array}{l}\text { Significance } \\
\text { of difference }\end{array}$} \\
\hline & $\begin{array}{c}\text { No of } \\
\text { women }\end{array}$ & $\operatorname{Mean}(\mathrm{SD})$ & $\begin{array}{l}\text { No of } \\
\text { women }\end{array}$ & $\operatorname{Mean}(\mathrm{SD})$ & \\
\hline \multicolumn{6}{|c|}{ Mean arterial pressure $(\mathrm{mm} \mathrm{Hg})$ : } \\
\hline Before treatment & 13 & $109(5 \cdot 7)$ & 16 & $110(6 \cdot 0)$ & NS \\
\hline During treatment & 13 & $100(9 \cdot 6)$ & 16 & $102(8 \cdot 6)$ & NS \\
\hline Mean (SD) change & & $-9 \cdot 0(6 \cdot 6)$ & & $-7 \cdot 8(6 \cdot 7)$ & NS \\
\hline Significance of difference & & $\mathrm{p}=0.003$ & & $\mathrm{p}=0.003$ & \\
\hline \multicolumn{6}{|l|}{ Maternal heart rate (beats/min): } \\
\hline Before treatment & 13 & $84(14 \cdot 5)$ & 16 & $91(12 \cdot 3)$ & NS \\
\hline During treatment & 13 & $69(13.0)$ & 16 & $88(8 \cdot 6)$ & $p=0.004$ \\
\hline Mean (SD) change & & $-15 \cdot 6(6 \cdot 3)$ & & $-4 \cdot 4(11 \cdot 5)$ & 0.005 \\
\hline Significance of difference & & $\mathrm{p}=0.0001$ & & NS & \\
\hline \multicolumn{6}{|c|}{ Arcuate artery pulsatility index: } \\
\hline Before treatment & 13 & $0.65(0.20)$ & 14 & $0.60(0.17)$ & NS \\
\hline During treatment & 13 & $0.73(0 \cdot 19)$ & 16 & $0.53(0.16)$ & $p=0.009$ \\
\hline Mean (SD) change & & $0.08(0.20)$ & & $-0.07(0.16)$ & NS \\
\hline Significance of difference & & NS & & NS & \\
\hline
\end{tabular}

TABLE III - Fetal haemodynamics before and during treatment of maternal hypertension

\begin{tabular}{|c|c|c|c|c|c|}
\hline & \multicolumn{2}{|c|}{ Atenolol group } & \multicolumn{2}{|c|}{ Pindolol group } & \multirow[b]{2}{*}{$\begin{array}{l}\text { Significance } \\
\text { of difference }\end{array}$} \\
\hline & $\begin{array}{l}\text { No of } \\
\text { women }\end{array}$ & $\operatorname{Mean}(\mathrm{SD})$ & $\begin{array}{l}\text { No of } \\
\text { women }\end{array}$ & $\operatorname{Mean}(\mathrm{SD})$ & \\
\hline \multicolumn{6}{|l|}{ Fetal heart rate (beats/min): } \\
\hline Before treatment & 13 & $144(10 \cdot 8)$ & 16 & $149(8 \cdot 8)$ & \\
\hline During treatment & 13 & $133(7 \cdot 8)$ & 16 & $144(6 \cdot 5)$ & $p=0.004$ \\
\hline Mean (SD) change & & $-11 \cdot 9(9 \cdot 6)$ & & $-5 \cdot 5(17 \cdot 1)$ & \\
\hline Significance of difference & & $\mathrm{p}=0.001$ & & NS & \\
\hline \multicolumn{6}{|c|}{ Thoracic aorta pulsatility index: } \\
\hline Before treatment & 13 & $1 \cdot 82(0 \cdot 20)$ & 16 & $1 \cdot 62(0 \cdot 30)$ & $p=0.04$ \\
\hline During treatment & 12 & $2.07(0.32)$ & 16 & $1.72(0 \cdot 35)$ & $\mathrm{p}=0.01$ \\
\hline Mean (SD) change & & $0.23(0.23)$ & & $0 \cdot 10(0 \cdot 35)$ & NS \\
\hline Significance of difference & & $\mathrm{p}=0.009$ & & NS & \\
\hline \multicolumn{6}{|c|}{ Abdominal aorta pulsatility index: } \\
\hline Before treatment & 12 & $1.44(0.28)$ & 14 & $1 \cdot 36(0 \cdot 29)$ & NS \\
\hline During treatment & 12 & $1.79(0.27)$ & 14 & $1.41(0.29)$ & $p=0.003$ \\
\hline Mean (SD) change & & $0.35(0.25)$ & & $0.05(0.29)$ & $\mathrm{p}=0.011$ \\
\hline Significance of difference & & $\mathrm{p}=0.008$ & & NS & \\
\hline \multicolumn{6}{|c|}{ Umbilical artery pulsatility index: } \\
\hline Before treatment & 13 & $0.93(0.17)$ & 16 & $0.89(0.30)$ & NS \\
\hline During treatment & 13 & $1.05(0 \cdot 19)$ & 16 & $0.79(0 \cdot 15)$ & $\mathrm{p}=0.04$ \\
\hline Mean (SD) change & & $0 \cdot 12(0 \cdot 14)$ & & $-0 \cdot 10(0 \cdot 20)$ & $\mathrm{p}=0.008$ \\
\hline Significance of difference & & $\mathrm{p}=0.011$ & & NS & \\
\hline \multicolumn{6}{|c|}{ Umbilical venous blood flow $(\mathrm{ml} / \mathrm{min} / \mathrm{kg})$ : } \\
\hline Before treatment & 11 & $106(28 \cdot 8)$ & 13 & $123(37 \cdot 5)$ & NS \\
\hline During treatment & 8 & $84(22 \cdot 6)$ & 11 & $148(50 \cdot 0)$ & $p=0.008$ \\
\hline Mean (SD) change & & $-32(23 \cdot 7)$ & & $25(43 \cdot 6)$ & $\mathrm{p}=0.008$ \\
\hline Significance of difference & & $p=0.012$ & & NS & \\
\hline
\end{tabular}

direction. Blood velocity (V) was recorded for at least 15 seconds in steady state, avoiding periods of fetal breathing and vigorous body movement. Vessel cross sectional area (A) was calculated from the mean value of 10 vessel diameters measured on 10 frozen real time images. The volumetric blood flow $(Q)$ in the fetal thoracic descending aorta and the intra-abdominal part of the umbilical vein was calculated according to the formula $\mathrm{Q}=\mathrm{V} \times \mathrm{A} / \cos 45^{\circ}$. Blood flow was related to fetal weight, estimated from the ultrasonically measured biparietal and abdominal diameters, ${ }^{9}$ and expressed in $\mathrm{ml} / \mathrm{min} / \mathrm{kg}$. The waveforms of the maximum velocity curves recorded from the descending aorta, the umbilical artery, and the maternal arcuate artery were characterised by the pulsatility index. Blood flow was measured twice, once before antihypertensive treatment and once on the seventh day of treatment. All ultrasound measurements were done at 1100 am under standardised conditions at the Ultrasound Blood Flow Laboratory in Malmö.

The main measures of outcome were maternal blood pressure, maternal and fetal heart rate, blood velocity waveforms in fetal aorta and umbilical artery, and umbilical venous blood flow. For each haemodynamic parameter the difference (during treatment-before treatment) was used as the effect variable and compared between treatment groups. We calculated that with 15 patients in each group there was an $80 \%$ probability of detecting a difference between groups of at least $106 \%$ of the standard deviation of the differences. For the umbilical artery pulsatility index we estimated a standard deviation of 0.15 and a detectable difference of about $0 \cdot 16$. For the aortal pulsatility indices we estimated a standard deviation of 0.25 and a detectable difference of about 0.27 .

A change in heart rate has been shown to influence the pulsatility index in the fetal descending aorta, maternal heart artery, and the arcuate artery. In our study a significant decrease in the fetal and maternal heart rate occurred during treatment, which might give a higher pulsatility index without the peripheral resistance having changed. Therefore the pulsatility index was always corrected for the heart rate-that is, it was normalised for a standard heart rate, according to reference values of our laboratory. ${ }^{112}$

The study was approved by the local ethics committee of the University of Lund. All women gave their informed consent. Statistical evaluation was done within the groups by $t$ tests for paired observations and between the groups by unpaired $t$ test. Fisher's exact test was used to evaluate differences in fetal outcome. A p value less than 0.05 was considered significant.

\section{Results}

Table I shows the characteristics of the women in the two groups. The mean duration of antihypertensive treatment did not differ between the atenolol and pindolol groups. Maternal mean arterial blood pressure was reduced after treatment by $9 \cdot 0(95 \%$ confidence interval -13.0 to -5.0$) \mathrm{mm} \mathrm{Hg}$ in the atenolol group and by $7 \cdot 8(-11 \cdot 4$ to $-4 \cdot 2) \mathrm{mm} \mathrm{Hg}$ in the pindolol group (table II). Maternal heart rate decreased in the atenolol group but was not altered in the pindolol group. Pulsatility index in the arcuate artery increased, though non-significantly, during treatment with atenolol (table II).

On average, 18 to 19 non-stress tests (range 9-33) were performed in each woman. A significant reduction in fetal heart rate was observed in women who received atenolol (table III). The volumetric blood flow did not change in the fetal aorta in either group. The umbilical venous blood flow, however, decreased significantly with atenolol, but slightly increased with pindolol (table III). 
The pulsatility index increased during atenolol treatment in fetal thoracic and abdominal aorta and in the umbilical artery. In contrast, during pindolol treatment the pulsatility index in the fetal blood vessels remained unchanged (table III). Five patients in each group had ominous changes in fetal heart during labour. Table IV shows the mode of delivery and fetal outcome. Two newborn infants in the pindolol group (one with pulmonary maladaptation, one with pneumothorax) and one in the atenolol group (fetal distress and pneumothorax) were referred to the neonatal intensive care unit. The birth weight, length at birth, and head circumference did not differ between the groups. Placental weight was significantly lower in women treated with atenolol.

TABLE IV - Mode of delivery and fetal outcome in women treated with atenolol and pindolol

\begin{tabular}{lcc}
\hline & $\begin{array}{c}\text { Atenolol } \\
\text { group } \\
(\mathrm{n}=13)\end{array}$ & $\begin{array}{c}\text { Pindolol } \\
\text { group } \\
(\mathrm{n}=16)\end{array}$ \\
\hline Fetal sex $(\mathrm{M} / \mathrm{F})$ & $8 / 5$ & $7 / 9$ \\
Mean (SD) birth weight $(\mathrm{g})$ & $3246(455)$ & $3398(569)$ \\
Mean (SD) length at birth $(\mathrm{cm})$ & $49 \cdot 6(2 \cdot 7)$ & $50 \cdot 0(2 \cdot 3)$ \\
No of caesarean section & 2 & 0 \\
No of vacuum extraction or forceps & 3 & 3 \\
No with Apgar score $<7:$ & 2 & 1 \\
$\quad$ At l minute & 1 & 0 \\
At 5 minutes & $529(122)^{\star}$ & $653(136)$ \\
Mean (SD) placental weight $(\mathrm{g})^{\star}$ & & \\
${ }^{\star} \mathrm{p}=0 \cdot 03$, Fisher's exact test. & &
\end{tabular}

No serious side effects were observed during treatment with the two $\beta$ blockers, and the drugs were well tolerated by the patients.

\section{Discussion}

Atenolol and pindolol lowered the blood pressure in women with pregnancy induced hypertension. A significant decrease in both maternal and fetal heart rate was seen in the atenolol group but not in the pindolol group, confirming previous findings. ${ }^{16}$

The most important findings were, however, that the pulsatility index and consequently the peripheral vascular resistance increased consistently in the fetal aorta and umbilical artery after atenolol treatment. No such changes were seen in the pindolol group.

Man In'T Veld and Schalekamp reviewed the acute and long term effects of different $\beta$ blockers. ${ }^{13}$ The properties of the drugs may differ in selectivity, metabolism, lipophilicity and hydrophilicity, and intrinsic sympathetic activity. A selective $\beta_{1}$ blocker reduces blood pressure mainly by reducing cardiac output. The immediate fall in blood pressure after administration of the drug is to some extent prevented by the vasoconstrictor activity mediated through the baroreflex. In long term treatment, however, the haemodynamic changes take the form of lower vascular tone rather than vasoconstrictor activity. Vasodilating properties have been shown in $\beta$ blockers with intrinsic sympathomimetic activity and attributed to stimulation by $\beta_{2}$ adrenoceptors. ${ }^{14}$ In animal tissues the intrinsic sympathomimetic activity of pindolol has been shown to vary between $10 \%$ and $50 \%$ of that of isoprenaline. ${ }^{15}$ In hypertensive rats pindolol reduced mean arterial blood pressure by reducing the total peripheral vascular resistance. ${ }^{16}$ Thus, non-selective $\beta$ blockers with intrinsic sympathomimetic activity are likely to reduce blood pressure by lowering peripheral vascular resistance and to have a minor effect on cardiac output.

The increase in pulsatility index during atenolol treatment indicates an increased peripheral vascular resistance. This is in line with the expected reflex vasoconstriction that can be seen when cardiac output is reduced. No effects on pulsatility index were seen during pindolol treatment, suggesting unchanged peripheral vascular resistance in the uteroplacental and fetal circulation. Owing to lack of knowledge of the sympathetic innervation in the fetus and placenta ${ }^{17}$ and of the type, distribution, and sensitivity of adrenoceptors in the developing fetus the mechanism behind the reaction can be only speculated on.

This is the first study in humans which shows decreased volumetric blood flow in umbilical veins during $\beta_{1}$ adrenoceptor blockade. The significant reduction in the atenolol group was observed after one week of treatment. By contrast, volumetric blood flow increased non-significantly in the pindolol group. In a previous study volumetric blood flow in the umbilical vein did not change during atenolol treatment on a short term basis (investigated after one and three days) ${ }^{6}$

\section{CONCLUSIONS}

In clinical practice Doppler ultrasound measurements of uteroplacental and fetal blood velocity waveforms might improve understanding of the haemodynamic situation and consequences of antihypertensive drugs and could also be of some value in the surveillance of the fetus once treatment has started. Significant effects on uteroplacental and fetal haemodynamics, although within normal ranges, were observed with a $\beta_{1}$ adrenoceptor blocker but not with a non-selective blocker with intrinsic sympathomimetic activity. We can only speculate on the clinical implications of our findings, but in pregnancies where uteroplacental and fetal blood flow is compromised before antihypertensive treatment is started, further deterioration of fetal haemodynamics as a result of $\beta_{1}$ adrenoceptor blockade cannot be excluded.

Birth weight and placental weight may be reduced if fetal haemodynamics are adversely affected. In a recent published placebo controlled trial both these parameters were significantly reduced after long term treatment with atenolol during pregnancy. ${ }^{18}$ Such adverse effects would be less after a short period of treatment, as in the present protocol (mean 16.6 days, range 7-43). Nevertheless, we also found that placental weight was significantly lower in the atenolol group than the pindolol group, a finding which might be related to concomitant changes in fetal haemodynamics.

We thank Anders Källén for statistical advice. The study was supported by grants from the Swedish Medical Research Council (grant Nos 7498 and 5980), the First of May Flower Campaign for Children's Health, and the Expressen Prenatal Research Foundation.

1 Rubin PC, Butters L, Clark DM, Reynolds B, Sumner DJ, Steedman D, et al Placebo controlled trial of atenolol in treatment of pregnancy-induced hypertension. Lancet 1983; i:431-4.

2 Rubin PC, Butters L, Clark DM. Obstetric aspects of the use in pregnancyassociated hypertension of the beta-adrenoceptor antagonist atenolol. Am f Obstet Gynecol 1984;150:389-92.

3 Reynolds B, Butters L, Evans J, Adam T, Rubin PC. The first year of life after use of atenolol in pregnancy associated hypertension. Arch Dis Child use of atenolol
$1984 ; 59: 1061-3$.

4 Kjellmer I, Dagbjartsson A, Hrebk A, Karlsson K, Rosen K-G. Maternal beta-adrenoceptor blockade reduces fetal tolerance to asphyxia. Acta Obstet beta-adrenoceptor blockade reduces fet

5 Karlsson K, Lundgren Y, Ljungblad U. The acute effects of non-selective $\beta$-adrenergic blocking agents in hypertensive rats. Acta Obstet Gynecol Scand 1984; Suppl 118:S81-4

6 Montan S, Liedholm H, Lingman G, Maršál K, Siöberg N-O, Solum T. Fetal and uteroplacental haemodynamics during short term atenolol treatment of hypertension in pregnancy. Br 7 Obstet Gynaecol 1987;94:312-7.

7 Lunell N-O, Nylund L, Lewander R, Sarby B, Wager J. Uteroplacental blood flow in pregnancy hypertension after the administration of a beta-adrenoceptor blocker, pindolol. Gynecol Obstet Invest 1984;18:269-74.

8 Lunell N-O, Hjelmdahs P, Fredholm BB, Lewander R, Nisell H, Nylund L, et al. Acute effects of labetalol on maternal metabolism and uteroplacental circulation in hypertension of pregnancy. In: Riley AJ, Symonds EM, eds. Proceedings of a symposium at the Royal College of Physicians, London, 2nd
December 1981. London: Royal College of Physicians, 1981:34-45. (Inter-
national congress series 591.)

9 Eik-Nes SH, Gröttum P, Andersson NJ. Estimation of fetal weight by 
ultrasound measurement. II. Clinical application of a new formula. Acta Obstet Gynecol Scand 1982;61:307-12.

10 Eik-Nes SH, Maršál K, Kristoffersen K. Methodology and basic problems related to blood flow studies in the human fetus. Ultrasound Med Biol 1984;10:329-37.

11 Lingman G, Maršal K. Fetal central blood circulation in the third trimester of normal pregnancy. Longitudinal study. II. Aortic blood velocity waveform. Early Hum Dev 1986;13:151-9.

12 Gudmundsson S, Maršal K. Umbilical artery and uteroplacental blood flow velocity waveforms in normal pregnancy-a cross-sectional study. Acta Obstet Gynecol Scand 1988;67:347-54.

13 Man In'T Veld AJ, Schalekamp MADH. How intrinsic sympathomimetic activity modulates the haemodynamic responses to $\beta$-adrenoceptor activity modulates the haemodynamic responses to $\beta$-adrenoceptor
antagonists. A clue to the nature of their antihypertensive mechanism. antagonists. A clue to the nature of their a
14 Thulesius $\mathrm{O}$, Gjöres JE, Berlin E. Vasodilating properties of beta-adrenoceptor blockers with intrinsic sympathomimetic activity. Br $\mathrm{f}$ Clin Pharmaco 1982;13:S229-30.

15 Clark BJ. Pharmacological analysis of the intrinsic sympathomimetic activity of pindolol: evidence for selective beta-2-adrenoceptor stimulation. Triangle 1984;23:33-8.

16 Lundgren Y, Karlsson K, Ljungblad U. Acute hemodynamic effects of pindolol during pregnancy in experimental renal hypertension. Acta Obstet Gynecol Scand 1984;Suppl 118:S85-90.

17 Duckles SP, Banner W Jr. Changes in vascular smooth muscle reactivity during development. Ann Rev Pharmacol Toxicol 1984;24:65-83.

18 Butters L, Kennedy S, Rubin PC. Atenolol in essential hypertension during pregnancy. $B M \mathcal{F}$ 1990;301:587-9.

(Accepted 21 fanuary 1992)

\title{
Review of management of incidents involving exposure to blood in a London teaching hospital, 1989-91
}

\author{
Katie Oakley, Christopher Gooch, Anne Cockcroft
}

\begin{abstract}
Objective-To review management of incidents involving exposure to blood reported to an occupational health unit.

Design-Analysis of all reported incidents from January 1989 to June 1991.

Setting-London teaching hospital.

Subjects -447 health care workers and students.

Main outcome measures-Immunisation against hepatitis $B$ virus before exposure, proportion of known source patients tested for hepatitis B surface antigen and HIV antibodies, and reasons for not testing known source patients.
\end{abstract}

Results -447 incidents were reported: 337 sharps injuries and 110 other exposures. 310 staff reporting incidents $(205(82 \%)$ nurses) were already immune to hepatitis B virus, nearly always because of immunisation. 345 source patients were identified, 77 of whom had already been tested for hepatitis $B$ surface antigen (28 positive results) and 58 for HIV antibodies (18 positive results). Of those not previously tested, 145 of 266 were subsequently tested for hepatitis B surface antigen (two positive) and 149 of 287 for HIV antibodies (none positive). The main reasons for not testing source patients were that the incident was not considered a risk, that the patient had gone home, and that the clinical team were unwilling to ask the patient. Specific hepatitis B immunoglobulin was given to 18 staff who were not immune and was avoided in 11 cases by a negative result for the patient. Prophylactic zidovudine was discussed but not given to any staff member.

Conclusions-Management of exposure to blood is improved by widespread immunisation against hepatitis $B$ virus and by knowledge of source patients' hepatitis B virus and HIV status.

Occupational Health Unit, Royal Free Hampstead NHS Trust and Royal Free Hospital School of Medicine, London NW3 20G

Katie Oakley, senior nurse Christopher Gooch, statistician

Anne Cockcroft, senior lecturer in occupational medicine

Correspondence to:

Dr Cockcroft.

BMF 1992;304:949-51

\section{Introduction}

Sharps injuries and other exposure to patients' blood carry a risk of transmission of bloodborne infections such as hepatitis B virus and HIV. Protection of staff requires immunisation against hepatitis $B$ virus, efforts to reduce the number of incidents, an effective reporting system, and proper management of reported incidents.

Since January 1989 when staff have been exposed to patients' blood our hospital has attempted to test the source patient for hepatitis B surface antigen and antibodies to HIV after counselling and consent, as is officially recommended in both Britain and the United States. ${ }^{2-4}$ Staff are encouraged to report incidents to our occupational health department and we contact the clinical team caring for the source patient asking them to approach the patient for the tests. Staff not immune to hepatitis B virus are given specific hepatitis B immunoglobulin if the source patient is positive for hepatitis B surface antigen. Prophylactic zidovudine is considered for exposures to blood containing HIV antibodies. We reviewed all exposures to blood reported to our unit during the two and a half years from January 1989 to June 1991.

\section{Methods}

Details of all reported incidents were recorded on a standard form which included the hepatitis B immunisation status and occupational group of the staff member, the hepatitis B virus and HIV status of the source patient, and whether the patient was tested as a result of the incident. Reasons for not testing known source patients were recorded.

One way frequency distributions were produced for each variable and relations between variables were analysed by generating two way frequency distributions. Overall relations between variables were assessed using Pearson's $\chi^{2}$ test for contingency. Percentage estimates and their confidence intervals were derived to compare particular categories within each of the variables.

\section{Results}

A total of 447 incidents was reported, 337 of which were incidents with needles or sharp instruments; there were 110 splash, bite, or scratch incidents. In 345 cases the source patient was known. Some patients had already been tested for hepatitis B surface antigen and HIV antibodies before the incident. One hundred and forty nine were tested for HIV antibodies and 145 for hepatitis B surface antigen because of the incident (table I). Eighteen of the patients were HIV positive; all had been tested before the incident. Thirty patients

TABLE I-Numbers of known source patients in blood exposure incidents tested for hepatitis $B$ surface antigen and HIV antibodies

\begin{tabular}{lcccc}
\hline & \multicolumn{4}{c}{ Tested for hepatitis B surface antigen } \\
\cline { 2 - 5 } $\begin{array}{l}\text { Tested for HIV } \\
\text { antibodies }\end{array}$ & $\begin{array}{c}\text { Before } \\
\text { incident }\end{array}$ & $\begin{array}{c}\text { After } \\
\text { incident }\end{array}$ & $\begin{array}{c}\text { Not } \\
\text { tested }\end{array}$ & Total \\
\hline $\begin{array}{lcccc}\text { Before incident } \\
\text { After incident }\end{array}$ & 48 & 4 & 4 & $58^{\star}$ \\
Not tested & 13 & 129 & 7 & 149 \\
\hline Total & 16 & 12 & 110 & 138 \\
\hline
\end{tabular}

$\star$ In two cases we could not determine whether the patient was tested for hepatitis B surface antigen. 